\title{
THE SPATIAL QUANTITATIVE EVALUATION AND COUPLING COORDINATION DEGREE OF URBAN ECOSYSTEM CARRYING CAPACITY: A CASE STUDY OF THE URBAN AGGLOMERATION IN THE MIDDLE REACHES OF THE YANGTZE RIVER, CHINA
}

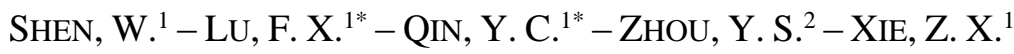 \\ ${ }^{1}$ College of Environment and Planning, Key Laboratory of Geospatial Technology for Middle \\ and Lower Yellow River Region, Henan University, Kaifeng 475004, China \\ (e-mail: shenwei@henu.edu.cn) \\ ${ }^{2}$ School of Surveying \& Land Information Engineering, Henan Polytechnic University \\ Jiaozuo 454000, China \\ "Corresponding authors \\ e-mail:qinyc@henu.edu.cn; Ifxhenu@126.com
}

(Received $30^{\text {th }}$ Jun 2019; accepted $16^{\text {th }}$ Oct 2019)

\begin{abstract}
The urban agglomeration in the middle reaches of the Yangtze River is within a typical ecologically sensitive area as well as it is a key development area in China. Scientific assessment of urban ecosystem carrying capacity has important scientific value and practical significance. In this study, we established a new assessment framework for urban ecosystem carrying capacity, and then based on the components and structural characteristics of urban ecosystems, we constructed an extended evaluation index system for urban ecosystem carrying capacity. Spatial analysis and a coupling coordination degree model were used to analyze spatial patterns and coupling coordination degree of urban ecosystem carrying capacity in urban agglomeration in the middle reaches of the Yangtze River in 2015. The results indicated that: (1) The urban ecosystem carrying capacity of the study area was spatially differentiated and clearly clustered. (2) Comprehensive coupling coordination in spatial distribution had a significant north-south differentiation pattern of study area. Highly coordinated cities were mainly distributed in the Poyang Lake urban agglomeration and the area around the Dongting Lake, while the less coordinated cities were mainly distributed in the Wuhan urban agglomeration and south of the urban agglomeration around Changsha-Zhuzhou-Xiangtan. (3) In the surrounding area of Wuhan City and southwest of the urban agglomeration around Changsha-Zhuzhou-Xiangtan of coupling coordination degree is low, mainly due to the backward industrial foundation, low economic development efficiency, and heavy load on resource consumption and the environment.
\end{abstract}

Keywords: urban ecosystem carrying capacity, moderate indicator, state-space model, coupling coordination degree model

\section{Introduction}

Since the 1990s, continuous promotion of reform and open policy and the gradual improvement of the market economy system have ushered, China's economy into a period of rapid growth (Qi et al., 2015). However, due to the rapid growth of urban population and built-up area, the overexploitation of natural resources, and environmental pollution had significant negative impacts on land cover, biodiversity, the hydrological system, and local climate at different regional scales. In turn, the natural environment has limited regional social and economic development, causing people to gradually realize that regional sustainable development is closely related to regional ecosystem health (Pei et al., 2019). Therefore, to guide the regional 
sustainable development, it is necessary to evaluate the urban ecosystem carrying capacity according to development status. Ecological carrying capacity is an important indicator, which is used for measuring the utilization degree of natural resources and interference intensity of ecological environment caused by human activities. Meanwhile, it is also an important tool for evaluating the level of regional sustainable development (Xiong et al., 2013). In recent years, it has attracted the attention of global scholars and has been widely used to evaluate urban ecosystem carrying capacity and sustainable development (Wackernagel and Galli, 2007; Zhang et al., 2016; Rudolph and Figge, 2017).

In 1922, Hawden and Palmerzai first proposed the concept of ecological carrying capacity when studying the impact of reindeer population on regional ecosystems. The concept was subsequently developed and improved, transforming from research focused on a single ecological element, to the early stage carrying capacity of an ecosystem (Cui and Yang, 1997; Hudak, 1999; Zhu et al., 2005), and finally to the carrying capacity of a composite ecosystem composed of integrated ecological elements such as nature, society and the economy (Wang et al., 2000; Yang and Sui, 2005; Xiong et al., 2014). The study of ecological carrying capacity based on comprehensive ecological factors has gradually enriched the theory and connotations of ecological carrying capacity, enhancing people's understanding of complex ecosystems. Evaluation methods and index systems for ecological carrying capacity, with the continuous development of the concept and connotation of ecological carrying capacity has also gradually improved with applications in different issues and research focuses. The main methods include human appropriation of net primary production (HANPP) (O’Neill et al., 2007; Sjafrie et al., 2018;), ecological footprint method (Jiao et al., 2011; Xiang et al., 2016; Peng et al., 2019), state-space method (Xiong et al., 2014; Ji et al., 2017), system model (Lein, 2010; He et al., 2011; Mondino et al., 2014; Ge et al., 2016), comprehensive evaluation method (Jin et al., 2015; Wang et al., 2017), ecosystem service consumption evaluation method (Rong et al., 2019), and more. Evaluation methods have the characteristics of diversification and synthesis (Ji et al., 2017).

Current research still has the following problems: in terms of the research on the evaluation index system of ecological carrying capacity, the selection of evaluation indicators has primarily focused on natural elements, and seldom considers the impacts of social development and progress, resource consumption, treatments for environmental pollution and other factors on the overall carrying capacity of a complex urban ecosystem, and the selection scope of indicators needs to be further expanded. From the perspective of the application of the state-space method, its calculation formula can be divided into two types: the first is represented by Xiong et al. (2014), Peng et al. (2016), Ji et al. (2017) and Pei et al. (2019), in which the statespace formula is used to calculate the urban ecosystem carrying capacity index a year or a time series. The advantages of this formula are well known and widely used, but it is unable to evaluate the state of the urban ecosystem carrying. The second type is represented by $\mathrm{Li}$ and $\mathrm{Ma}$ (2013) and Song and $\mathrm{Yu}$ (2014), and is used to calculate current and ideal values for urban ecosystem carrying capacity in a cross-section of a year, and then evaluates carrying status of urban ecosystem based on the difference between current and ideal values. The advantage of this formula is that it can quantitatively evaluate the carrying status of an urban ecosystem. In summary, two issues remain in the application of the state-space method: first, moderate indices are 
seldom mentioned and the forward processing formulas for them have not been clearly described; Secondly, selecting ideal values for each index need to update. In addition, research on urban ecosystem carrying capacity based on the state space method has focused more on the analysis of spatial and temporal patterns, and less on an in-depth analysis of the coupling and coordination among the dimensions of the state-space axis and their causes.

The middle reaches of china's Yangtze River is an ecologically sensitive region that shoulders the important responsibility of ecological protection in the Yangtze river basin of China. At the same time, it is also one of the regions with the densest population, the highest intensity of water and soil resources development and utilization, and the most severe environmental pollution problems in China. At present, there has not been in-depth research on spatial pattern of the carrying state of the urban ecosystem and the level of coupling coordination between dimensions of urban agglomeration in the middle reaches of the Yangtze River. In light of deficiencies in the current research on the evaluation index system for urban ecosystem carrying capacity and applications of state-space method, firstly, our research established a new assessment framework for urban ecosystem carrying capacity and used multi-source data to construct a comprehensive evaluation index system composed by 25 key indicators. Meanwhile, these indicators are selected to depict urban ecosystem carrying capacity in terms of three aspects: the social-economic coordination force, resource-environment supporting force, and ecological resilience. Secondly, we improved the forward processing formula of moderate indicators and determined the ideal value of all indicators. Thirdly, we used the state-space method and coupling coordination degree model to analysis the spital pattern and coupling coordination of urban ecosystem carrying capacity in urban agglomeration in the middle reaches of the Yangtze River in 2015. This study complemented the theoretical and methodological studies of urban ecological carrying capacity, and this paper also has important practical significance and scientific value in guiding the sustainable development of the urban agglomerations in the middle reaches of the Yangtze river.

\section{Study area and data source}

\section{Study area}

The Urban agglomeration in the middle reach of the Yangtze River is a super urban agglomeration formed by the Wuhan urban agglomeration, the Poyang lake urban agglomeration, and the Changsha-Zhuzhou-Xiangtan urban agglomeration. It is located in the middle of China's Yangtze River basin, including a total of 31 prefecture-level cities and some counties (districts) in Hubei, Hunan, and Jiangxi Provinces. Lying at $26^{\circ} 03^{\prime} \sim$ $32^{\circ} 38^{\prime} \mathrm{N}, 110^{\circ} 45^{\prime} \sim 118^{\circ} 21^{\prime} \mathrm{E}$ and with a total area of about 326000 square kilometers, the region has a subtropical monsoon climate with annual average rainfall of about 800-1943 $\mathrm{mm}$. The Urban agglomeration in the middle reaches of the Yangtze river is dominated by plains (Fig. 1), with fertile soil and abundant water resources. It is home to Poyang and Dongting Lake, the Han and Qingjiang Rivers, and many other rivers and lakes, with a good combination of water, temperature, and abundant agricultural resources that makes it one of the major grain-producing areas in China. However, the urban agglomeration in the middle reaches of the Yangtze river in this densely populated area and important development zone for Jiangxi, Hubei, and Hunan Provinces has been experienced 
prominent problems in recent years, such as carrying pressure of water resource, ecological security, and land pollution (Li et al., 2017; Chen et al., 2018).

\section{Data source}

The socio-economic statistical data used in this paper were obtained from 《China urban statistical yearbook of 2016》, 《Jiangxi statistical yearbook of 2016》, 《Hubei statistical yearbook of 2016》, 《Hunan statistical yearbook of 2016》, and 《China urban construction statistical yearbook of 2016》. Land use/cover data (for Jiangxi, Hubei, and Hunan provinces) were downloaded from the national science and technology infrastructure platform -- national earth system science data sharing platform (http://www.geodata.cn). A Python script was used for batch segmentation, transformation and extraction of 2015 land use/cover data, and then the forest and wetland data from each research unit was subdivided and counted (land cover data was available in five year intervals, the year 2015 with relatively complete data was selected as the study period). In addition, data on missing indicators such as total water resources were obtained from the water resources bulletin, total arable land area and urban and rural residential income were obtained from the statistics bulletin of prefecture-level cities.

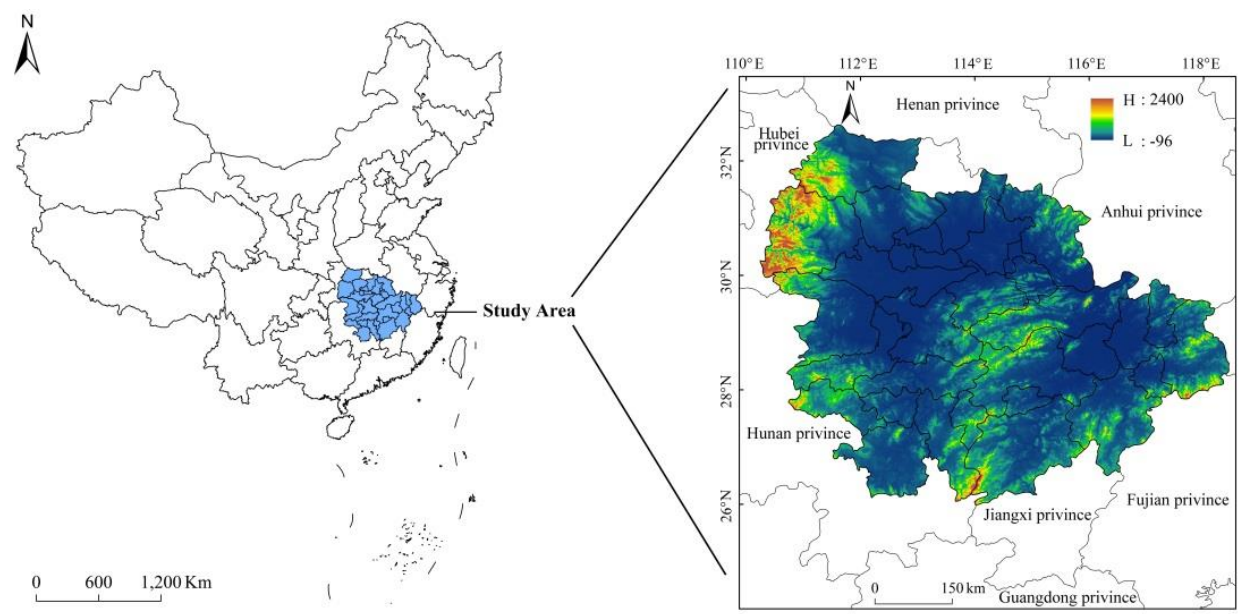

Figure 1. Location of the study area

\section{Methodology}

\section{Framework of urban ecosystem carrying capacity assessment}

There is no uniform concept of urban ecosystem carrying capacity, but by integrating existing research in this paper (Yin et al., 2011; Xiong et al., 2016; Wang et al., 2017; Pan et al., 2017), the concept was defined as: In a certain period and under a certain level of pressure, the urban ecosystem can maintain its own healthy and coordinated development carrying capacity. It is mainly manifested in three parts: the coordination ability generated by the socio-economic subsystem, the supporting ability provided by the resource-environment subsystem to maintain the healthy operation of the system, and the regulating ability and development potential of the ecological resilience subsystem to achieve an appropriate goal. 
We referred to existing studies on urban ecosystem carrying capacity and established a new framework for urban ecosystem carrying capacity assessment, we call it "pressure and driving force - supporting force - regulating force" model. As indicated in Fig. 2, the framework of urban ecosystem carrying capacity assessment includes the state plane (plane XY) and development potential axis (axis Z), which together constitute the overall development state of urban ecosystem carrying capacity. The evaluation framework also includes three dimensions: social-economic coordination force, resource-environment support force, and ecological resilience. These take into account the pressure and driving forces behind the social and economic subsystem, the supporting forces of resources and environment subsystem, and the regulating forces and development potential of the ecological subsystem.

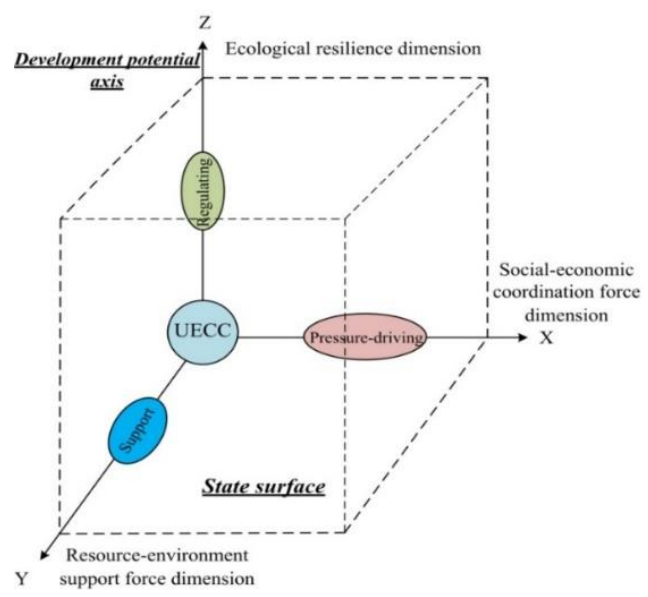

Figure 2. Framework of urban ecosystem carrying capacity (UECC) assessment

The composition and functions of the three dimensions of urban ecosystem carrying capacity can be further explained as follows: (1) Social-economic coordination force is the "pressure-driving" part of urban ecosystem carrying capacity. Social and economic coordination force not only reflects unbalanced social development pressure, population bearing pressure, and economic development pressure faced by urban ecosystem, but also reflects driving forces behind social progress, economic improvement, and industrial structure optimization for the overall development of urban ecosystem. (2) Resource-environment supporting force is the supporting and guaranteeing part of urban ecosystem, which reflects the degree of coordination between the supply of regional resource-environment and the demand of social-economic development. (3) Ecological resilience is the regulating part of urban ecosystem, which reflects the regulating power of regional ecological environment, and the development potential generated by human factors acting on the ecological environment.

\section{Index system for urban ecosystem carrying capacity assessment}

The purpose of establishing a comprehensive evaluation index system of urban ecosystem carrying capacity is to represent the degree of coordination between the regional socioeconomic system and resource-environmental system, and to reflect the carrying capacity of urban complex ecosystem. This paper first considers the component and the structure characteristics of urban ecosystem, takes the impact of human activities as the context, on the 
basis of fully considering the characteristics of the study area, the comprehensive evaluation index system of urban ecosystem carrying capacity is established (Table 1). An extensive literature review was instrumental in selecting evaluation indicators. On the one hand, we selected indicators that are generally recognized and widely used by scholars in related fields (Xiong et al., 2013; Jin et al., 2015; Rudolph and Figge, 2017; Ji et al., 2017; Wang et al., 2017; Pei et al., 2019; Rong et al., 2019). On the other hand, we fully considered the impacts of social development and progress, resource consumption and environmental pollution control on urban ecosystem carrying capacity, making this paper somewhat innovative in the construction of index system.

Table 1. Indicators for urban ecosystem carrying capacity assessment

\begin{tabular}{|c|c|c|c|c|}
\hline $\begin{array}{c}\text { System } \\
\text { layer }\end{array}$ & $\begin{array}{c}\text { Subsystem } \\
\text { layer }\end{array}$ & $\begin{array}{c}\text { Criterion } \\
\text { layer }\end{array}$ & Basic index layer & $\begin{array}{c}\text { Properties } \\
\text { of index }\end{array}$ \\
\hline \multirow{25}{*}{$\begin{array}{l}\text { Urban } \\
\text { ecosystem } \\
\text { carrying } \\
\text { capacity }\end{array}$} & \multirow{13}{*}{$\begin{array}{l}\text { Social-economic } \\
\text { coordination force }\end{array}$} & \multirow{5}{*}{$\begin{array}{l}\text { Social progress } \\
\text { factor }\end{array}$} & $\begin{array}{l}\text { X1: Ratio of annual disposable urban household } \\
\text { income to rural household income }\end{array}$ & Negative \\
\hline & & & $\begin{array}{l}\text { X2: Ratio of annual urban household } \\
\text { comsumption to rural household comsumption }\end{array}$ & Negative \\
\hline & & & X3: Highway passenger volume per capita & Positive \\
\hline & & & X4: Hospital beds amount of every $10^{4}$ people & Positive \\
\hline & & & X5: Buses and trams amount of every $10^{4}$ people & Positive \\
\hline & & \multirow{3}{*}{$\begin{array}{c}\text { Population } \\
\text { development factor }\end{array}$} & X6: Population density & Moderate \\
\hline & & & X7: Natural rate of population growth & Moderate \\
\hline & & & X8: Population urbanization rate & Moderate \\
\hline & & \multirow{3}{*}{$\begin{array}{c}\text { Economic } \\
\text { development factor }\end{array}$} & X9: Growth rate of per capita GDP & Moderate \\
\hline & & & $\mathrm{X} 10$ : Energy consumption per $10^{4} \mathrm{GDP}$ & Negative \\
\hline & & & X11: Per capita GDP & Positive \\
\hline & & \multirow{2}{*}{$\begin{array}{l}\text { Industrial structure } \\
\text { factor }\end{array}$} & $\begin{array}{l}\text { X12: The percentage of the primary industry } \\
\text { output value }\end{array}$ & Moderate \\
\hline & & & $\begin{array}{c}\text { X13: The percentage of the tertiary industry output } \\
\text { value }\end{array}$ & Positive \\
\hline & \multirow{7}{*}{$\begin{array}{c}\text { Resource- } \\
\text { environment } \\
\text { supporting force }\end{array}$} & \multirow{2}{*}{$\begin{array}{l}\text { Resource support } \\
\text { factor }\end{array}$} & X14: Water resources per capita & Positive \\
\hline & & & X15: Cultivated area per capita & Positive \\
\hline & & \multirow{5}{*}{$\begin{array}{c}\text { Environmental } \\
\text { management factor }\end{array}$} & $\begin{array}{l}\text { X16: Comprehensive utilization rate of industrial } \\
\text { solid waste }\end{array}$ & Positive \\
\hline & & & $\begin{array}{c}\text { X17: Treatment rate of industrial smoke (powder) } \\
\text { dust }\end{array}$ & Positive \\
\hline & & & $\begin{array}{c}\text { X18: Standard discharge rate of industrial } \\
\text { wastewater }\end{array}$ & Positive \\
\hline & & & X19: Domestic sewage treatment rate & Positive \\
\hline & & & X20: Domestic waste treatment rate & Positive \\
\hline & \multirow{5}{*}{ Ecological resilience } & \multirow{4}{*}{$\begin{array}{l}\text { Ecological } \\
\text { resilience factor }\end{array}$} & $\mathrm{X} 21$ : Forest coverage rate & Positive \\
\hline & & & $\begin{array}{c}\mathrm{X} 22 \text { : The percentage of wetland area to total } \\
\text { area }\end{array}$ & Positive \\
\hline & & & X23: Green coverage rate in built-up area & Positive \\
\hline & & & X24: Per capita public green area & Positive \\
\hline & & $\begin{array}{c}\text { Ecological } \\
\text { potential factor }\end{array}$ & $\begin{array}{l}\text { X25: Per capita investment in science and } \\
\text { technology }\end{array}$ & Positive \\
\hline
\end{tabular}

Note: data of indicators X3 X13 and X23 X25 are from Jiangxi statistical yearbook of 2016, Hubei statistical yearbook of 2016, and Hunan statistical yearbook of 2016. Data of indicators X16 X20 are from China urban statistical yearbook of 2016 and China urban construction statistical yearbook of 2016. Data of indicators X21 X22 are derived from the data of land use/cover in 2015. Data of indicators X1, X2 , and X15 data are from the prefecture level statistical bulletin. Data of indicator X14 is from the prefecture level water resources bulletin 


\section{Preprocessing of index data and weight determination}

In the process of index data processing, in order to eliminate the possible differences in dimension and magnitude between indices, it was necessary to carry out forward processing and standardized processing of the index data. First, we selected negative indicator for forward processing, referenced the relevant research (Hu et al., 1992), and improved the existing formula, make the value compression after forward processing as $(0,1]$, there will be no height anomalies of $x_{i j}^{z}=0$ and avoided the subsequent difficulty of logarithmic operations. The forward processing formula for the negative indicator is:

$$
x_{i j}^{Z}=\frac{\operatorname{MAX}\left(x_{i j}\right)-x_{i j}}{\operatorname{MAX}\left(x_{i j}\right)-\operatorname{MIN}\left(x_{i j}\right)}+0.001
$$

The forward processing formula for the moderate indicator had not been derived out by existing studies. This study attempts to derive the formula, after verifying several different types of sample data, and found that the dimensionality of the data after the forward calculation by this formula was eliminated. The forward processing formula is as follows:

$$
x_{i j}^{Z}= \begin{cases}\frac{1}{\left(1+\left|1-\frac{x_{i j}}{A_{i}}\right|\right)} & , x_{i j}<A_{i} \\ \frac{1}{\left(1+\left|\frac{x_{i j}}{A_{i}}-1\right|\right)}, & x_{i j} \geq A_{i}\end{cases}
$$

In the above equation (1) and (2): $x_{i j}$ is the original index value, $x_{i j}^{Z}$ is the forward value of the original index, $\operatorname{MAX}\left(x_{i j}\right)$ is the maximum value of the $j$ year and the ith index, $\operatorname{MIN}\left(x_{i j}\right)$ is the minimum value of the $j$ year and the $i$ th index, and $A_{i}$ is the optimal threshold of the moderate index. By referring to relevant literature (Zhou and Zhao, 2012; Xiao et al., 2013) and consulting experts in relevant fields, the optimal thresholds for GDP growth rate index and the proportion of primary industry in GDP indices were set as $7 \%$ and $12.4 \%$, respectively. GDP growth rate and the proportion of the primary industry in GDP were defined as moderate indicators based on the following considerations: (1) Zhou and Zhao (2012) have shown that the GDP growth rate is $7 \%$ or lower, which will lead to employment pressure, inflation, and other problems. Therefore, there is an optimal threshold for GDP growth rate. (2) The primary industry usually includes agriculture, forestry, animal husbandry, fishery and other agricultural industries, which provide the basic energy supply for the urban ecosystem. A low proportion of the primary industry affects urban ecosystem stability, while a high proportion is not conducive to the improvement of social and economic coordination. Xiao et al. (2013) pointed out that there is an optimal proportion in the primary industry. In addition, the optimal thresholds for population density, natural population growth rate, and population urbanization rate were set as 600 people $/ \mathrm{km}^{2}, 5 \%$ o and 60\%, respectively, based to relevant research ( $\mathrm{Li}$ and $\mathrm{Li}, 2014 ; \mathrm{Su}$ et al., 2019).

After the forward processing of the negative and moderate indicator, the positive and moderate indicator values were standardized after the forward processing are standardized. In this paper, the maximum and minimum value standardization method was adopted to standardize the data. Considering that the index data in this paper were resources, environment and socio-economic indicators based on the statistics of 
administrative units, the weights of evaluation indicators were determined by the entropy weight method (Ji et al., 2017; Wang et al., 2017). The entropy weight method is an objective weighting method, it can avoid the interference of human subjective factors and make the result have objectivity and higher credibility (Shen et al., 2017).

\section{State-space method}

The state space method is an effective method for quantitative describing system state in Euclidean geometry space. It is usually composed of three-dimensional state space axes representing the state vectors of each element of the system. In the three dimensional state space, each point represents the spatial combination of resourceenvironment and human social-economic activities over a certain period of time, and a specific carrying state of the system can be judged by the position of the points (Ji et al., 2017). The formula for calculating the ideal value (ECC) and the current value (ECS) of urban ecosystem carrying capacity are as follows:

$$
\begin{gathered}
E C C=\sqrt{\sum_{i=1}^{n} w_{i}^{2}} \\
E C S=\sqrt{\sum_{i=1}^{n}\left(w_{i} * x_{i j}^{b}\right)^{2}}
\end{gathered}
$$

In Equations (3) and (4), $w_{i}$ is the index weight, and $x_{i j}^{b}$ is the ratio coefficient between the original value of each city index and its ideal value (Table 2) based on the ratio method according to the differences in the three types of indices. The specific calculation process is shown in Equation (5). The main considerations for determining ideal value of all indices are the sustainability and internal coordination of the urban ecosystem, and experts in related fields were consulted for revision.

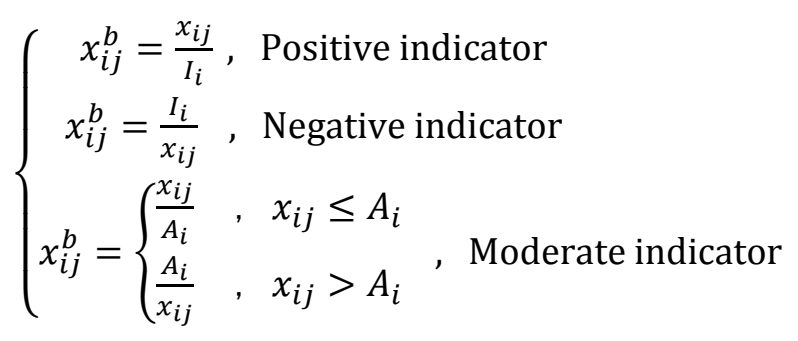

\section{Coupling coordination degree model}

Referring to the coupling model for capacity in physics, the coupling model for two systems (Equation (6)) and three systems (Equation (7)) were generalized to explore the coupling coordination relationship between the three dimensions: "social-economy, resource-environment, and ecological resilience" (Xing et al., 2019). The model formula is as follows:

$$
C=\left\{\frac{f(x) \cdot g(y)}{\left[\frac{f(x)+g(y)}{2}\right]^{2}}\right\}^{\frac{1}{2}}
$$




$$
C=\left\{\frac{f(x) \cdot g(y) \cdot h(z)}{\left[\frac{f(x)+g(y)+h(z)}{3}\right]^{3}}\right\}^{\frac{1}{3}}
$$

In the formula, $f(x), g(y)$ and $h(z)$ are respective standardized values of carrying capacity for the three dimensions. $C$ is the coupling degree, which ranges from $0-1$. Since the coupling degree can only measure the degree of correlation among dimensions, but cannot reflect the coordination level among dimensions, this paper further introduced a coupling coordination degree model, so as to better measure the coupling coordination level among dimensions. The formula is as follows:

$$
\begin{gathered}
D=\sqrt{C \cdot T} \\
T=\alpha f(x)+\beta g(y)+\gamma h(z)
\end{gathered}
$$

In Equations (8) and (9), D is the coupling coordination degree ranging from 0-1 and $T$ is used to measure the overall synergy between dimensions. $\alpha, \beta, \gamma$ are undetermined coefficients representing the contribution of each dimension. We assumed that the three dimensions were equally important to urban ecosystem carrying capacity, so $\alpha=\beta=\gamma$ $=1 / 3$.

\section{Results}

\section{Evaluation of the urban ecosystem carrying capacity in urban agglomeration in the middle reaches of the Yangtze River}

According to the state-space method, the ideal value for urban ecosystem carrying capacity was $\mathrm{ECC}=0.216$, and the ideal value of social-economic coordination force dimension, resource-environment support force dimension and ecological elastic force are $0.154,0.133$ and 0.07 , respectively. In order to judge the carrying state of urban ecosystem, the carrying state index is introduced as CSI. According to the principle of state-space method, CSI = ECS-ECC, and when CSI $>0$, the system is in a loadable state. When CSI=0, the system is in a fully loaded state. When CSI $<0$, the system is overloaded. Based on urban ecosystem carrying capacity, the ideal value of the three dimensions, and the CSI, 28 cities were divided into six state types8: highly loadable area $(\mathrm{CSI}>0.05)$, moderately loadable area $(0.02<\mathrm{CSI} \leq 0.05)$, mildly loadable area $(0<\mathrm{CSI} \leq 0.02)$, fully loaded area $(\mathrm{CSI}=0)$, mildly overloaded area $(-0.02 \leq \mathrm{CSI}<0)$, moderately overloaded area $(-0.05<\mathrm{CSI} \leq-0.02)$.

By virtue of the spatial visualization function of ArcGIS10.3 software was used to visualize, the CSI of the urban ecosystem and three dimensions in 2015 was visualized in accordance with the carrying state classification criteria above (Fig. 3).

The social-economic coordination force dimension is the "pressure-driven" part of urban ecological carrying capacity. It not only reflects unbalanced social development pressure, population pressure and economic development pressures faced by an urban ecosystem, but also the development ability provided by social progress, economic strength, and industrial optimization. From the perspective of spatial distribution characteristics (Fig. 3a), the dimension had a circling spatial structure extending outward from the provincial capitals of Hubei, Hunan, and Jiangxi Provinces. 
Table 2. Ideal values and sources for each indicator

\begin{tabular}{|c|c|c|}
\hline Basic index layer & Ideal value & Source of the ideal value \\
\hline $\begin{array}{l}\text { X1: Ratio of annual disposable urban household } \\
\text { income to rural household income }\end{array}$ & 1.7 & Su et al., 2019 \\
\hline $\begin{array}{l}\text { X2: Ratio of annual urban household } \\
\text { consumption to rural household consumption }\end{array}$ & 2.0 & Chen and $\mathrm{Wu}, 2017$ \\
\hline X3: Highway passenger volume per capita & 17 & Expert consultation method \\
\hline X4: Hospital beds amount of per $10^{4}$ people & 40 & China habitat award standards of 2016 \\
\hline X5: Buses and trams amount of per $10^{4}$ people & 15 & $\begin{array}{l}\text { "China's 13th five-year" plan for urban public } \\
\text { transport development targets }\end{array}$ \\
\hline X6: Population density & 600 & China habitat award standards of 2016 \\
\hline X7: Natural population growth rate & 5 & Zhou and Yin, 2012 \\
\hline X8: Population urbanization rate & 60.0 & Su et al., 2019 \\
\hline X9: Growth rate of per capita GDP & 7 & Zhou et al., 2012 \\
\hline X10: Energy consumption per $10^{4} \mathrm{GDP}$ & 0.68 & China habitat award standards of 2016 \\
\hline X11: Per capita GDP & 50000 & Peng et al., 2016 \\
\hline $\begin{array}{l}\text { X12: The percentage of the primary industry } \\
\text { output value }\end{array}$ & 12.4 & Xiao et al., 2013 \\
\hline $\begin{array}{l}\text { X13: The percentage of the tertiary industry } \\
\text { output value }\end{array}$ & 50.00 & China habitat award standards of 2016 \\
\hline X14: Water resources per capita & 1700 & $\begin{array}{c}\text { Comprehensive report on China's water resources } \\
\text { strategy for sustainable development }\end{array}$ \\
\hline X15: Cultivated area per capita & 533 & $\begin{array}{l}\mathrm{UN} \text { food and agriculture organization, per capita } \\
\text { arable land area warning line }\end{array}$ \\
\hline $\begin{array}{l}\text { X16: Comprehensive utilization rate of } \\
\text { industrial solid waste }\end{array}$ & 90 & $\begin{array}{c}\text { National model city standard for environmental } \\
\text { protection }\end{array}$ \\
\hline $\begin{array}{l}\text { X17: Treatment rate of industrial smoke } \\
\text { (powder) dust }\end{array}$ & 95.00 & $\begin{array}{l}\text { National model city standard for environmental } \\
\text { protection }\end{array}$ \\
\hline $\begin{array}{c}\text { X18: Standard discharge rate of industrial } \\
\text { wastewater }\end{array}$ & 80.00 & Li and Ma, 2013 \\
\hline X19: Domestic sewage treatment rate & 80.00 & $\begin{array}{l}\text { National garden city series standards of } 2015 \\
\text { national garden city series standards }\end{array}$ \\
\hline X20: Domestic waste treatment rate & 100 & China habitat award standards of 2016 \\
\hline $\mathrm{X} 21$ : Forest coverage rate & 47.00 & Su et al., 2019 \\
\hline $\begin{array}{l}\text { X22: The percentage of the wetland area to the } \\
\text { total area }\end{array}$ & 6.00 & Xiong et al., 2014 \\
\hline X23: Green coverage rate in built-up area & 45 & China habitat award standards of 2016 \\
\hline X24: Per capita public green area & 15.0 & Su et al., 2019 \\
\hline $\begin{array}{c}\text { X25: Per capita investment in science and } \\
\text { technology }\end{array}$ & 200 & Expert consultation method \\
\hline
\end{tabular}

As shown in Figure 3, the proportion of each carrying state grade in the socialeconomic coordination force dimension is relatively balanced, but the spatial differentiation was obvious. In detail, light and moderately overload areas were mainly distributed around provincial capitals in Hubei, Hunan and Jiangxi Provinces. This is because the surrounding areas of provincial capitals are in a stage of rapid urbanization, social infrastructure is not perfect, and the urban-rural dual structure is still prominent. In addition, due to poor industrial foundation and undertake capital of core city "three highs" (high pollution, high energy consumption, high emissions) industrial transfer and other reasons, led to a higher proportion of the primary and secondary industries and low economic development efficiency. Low loadable areas were scattered in the central and southeastern parts of the urban agglomeration. Moderately loadable and highly loadable areas were mainly distributed in Xiangyang-Jingmen-Yichang urban belt and 
the provincial capital city. The high carrying capacity of provincial capital city has benefited from good infrastructure, strong economic power, and reasonable industrial structure, which resulted in strong ability of coordination. To some extent, this has also limited the negative impacts due to the large urban population.

The resource-environment supporting force dimension is the supporting and guaranteeing component of urban ecosystem carrying capacity, which reflects the degree of coordination between the supply of regional resource and the demands of social-economic development. From the perspective of spatial distribution characteristics (Fig. 3b), the resource-environment support force dimension presents a pattern of north-south differentiation, and it had obvious spatial characteristics of homogeneous agglomeration.

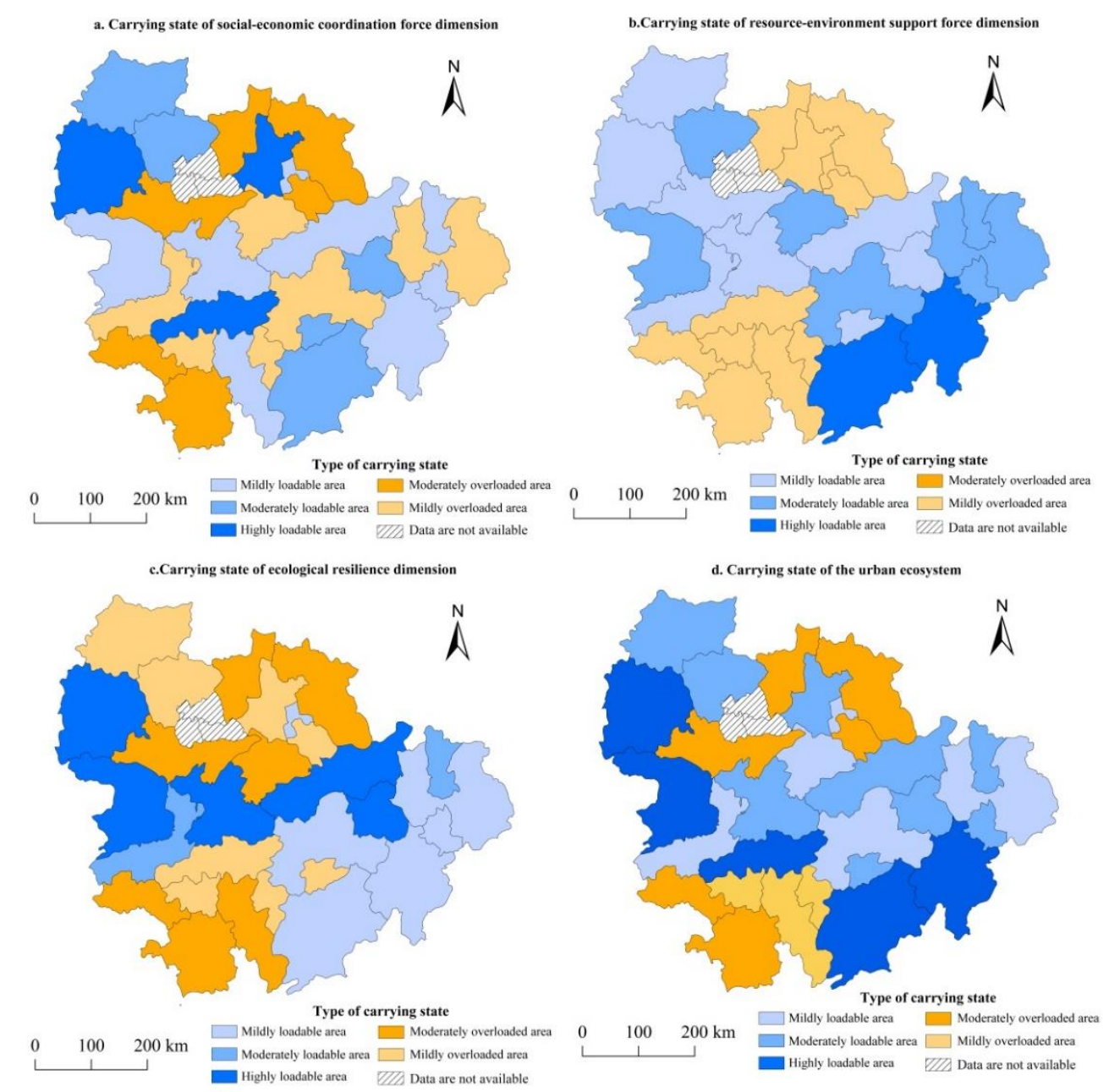

Figure 3. The spatial pattern of urban ecosystem carrying capacity in the middle reaches of the Yangtze River in 2015

As shown in Figure 3, the proportion of each carrying state grade in the resourceenvironment supporting force dimension is extremely unequal, and low, medium, and high loadable areas accounted for nearly $65 \%$ of the total. In detail, the mildly overload area was mainly distributed in the core area of Wuhan urban agglomeration, and the urban agglomeration around Changsha-Zhuzhou-Xiangtan. The reasons for this are as follows: On 
the one hand, population clustering and industrial development in these two areas created great resource supply pressure. On the other hand, regional environmental pollution has not attracted enough attention, resulting in serious environmental pollution. The conflicts between accelerated industrialization and resource-environment constraints were prominent. Light and moderately loadable areas were mainly distributed in the Xiangyang-JingmenYichang urban belt, Poyang Lake urban agglomeration, and the area around Dongting Lake. Poyang Lake urban agglomeration and the area around Dongting Lake are rich in natural resources, so the regional resource supply pressure is small. In addition, recent implementation of ecological and environmental protection policies in the region (《Dongting Lake ecological economic zone planning》, 《Poyang Lake ecological urban agglomeration planning (2015-2030)》, and 《Yangtze River economic zone ecological environmental protection planning 》) has further improved the control of regional environmental pollution. Xiangyang and Yichang cities have also recently made efforts to build themselves into two major sub-central cities in Hubei Province. The resource and environmental protection in Xiangyang-Jingmen-Yichang urban belt has received great attention, and the regional resource and environmental support level has been continuously improved.

The ecological resilience dimension is the regulating part of urban ecosystem carrying capacity, which reflects the regulating ability of the regional environment and the ecological potential of human acting on the ecological environment. From the perspective of spatial distribution characteristics (Fig. 3c), this dimension had a spatial the pattern of north-south differentiation, and it had obvious spatial characteristics of homogeneous agglomeration. As shown in Figure 3, the proportion of each carrying status grade was relatively balanced. In detail, light and moderately overload areas were mainly distributed in the core areas of the Wuhan urban agglomeration and the urban agglomeration around Changsha-ZhuzhouXiangtan. Light, moderately, and highly loadable areas were mainly distributed around Dongting and Poyang Lakes, and Yichang city in Hubei province. Investigate its reason, the ecological environment conditions of the core region of the Wuhan urban agglomeration and the urban agglomeration around Changsha-Zhuzhou-Xiangtan were worse than the region of Dongting Lake and Poyang Lake, and in recent years, the Wuhan urban agglomeration and the urban agglomeration around Changsha-Zhuzhou-Xiangtan of the rapid advance of urbanization are in the stage of rapid urbanization. The rapid expansion of urban construction area has gradually nibbled away natural elements such as vegetation and wetlands, lowering ecological resilience. Yichang City on the Yangtze River is a national garden, health, and forest city, and the only national model city for environmental protection in Hubei Province. It therefore has great environment background conditions. In addition, Yichang city's economic strength and scientific-technological level are among the highest in Hubei Province with great ecological potential.

Urban ecosystem carrying capacity is a functional status formed by the structural action of the three dimensions, which reflects the comprehensive carrying capacity of urban ecosystem. From the perspective of spatial distribution characteristics (Fig. 3d), the carrying capacity of urban ecosystem presents a significant north-south spatial differentiation pattern, and it had obvious spatial characteristics of homogeneous agglomeration. As shown in Figure 4, the proportion of each urban ecosystem carrying status grade was extremely unequal, the types of low, moderately and highly loadable areas accounted for nearly $70 \%$ of the total, so the overall carrying state of the urban ecosystem in study area was relatively good. In detail, the light and moderately overloaded areas were mainly distributed in the surrounding areas of Wuhan and Changsha. Light, moderately and highly loadable areas 
were mainly distributed in the Xiangyang-Jingmen-Yichang urban belt, and around Dongting and Poyang Lakes. Investigate its reason, although the resource-environment and ecological resilience dimensions in Wuhan and Changsha were slightly overloaded, the overall urban ecosystem were in a loadable state due to their strong social-economic coordination. In their surrounding areas, all dimensions were mostly in the overload state. Low efficiency economic development, urban-rural dual development structure, ecological destruction, and environmental pollution caused by urban population growth and industrial development are the main causes. Rings of Dongting and Poyang Lakes region, as well as the Xiangyang-Jingmen-Yichang urban belt, benefited from strong resources-environment support force and ecological resilience dimensions. In the future, on the premise of maintaining green economic development and protecting environment, we should focus on optimizing regional social infrastructure, improving economic development efficiency and optimizing industrial structure, so as to improve social-economic coordination force in the region.

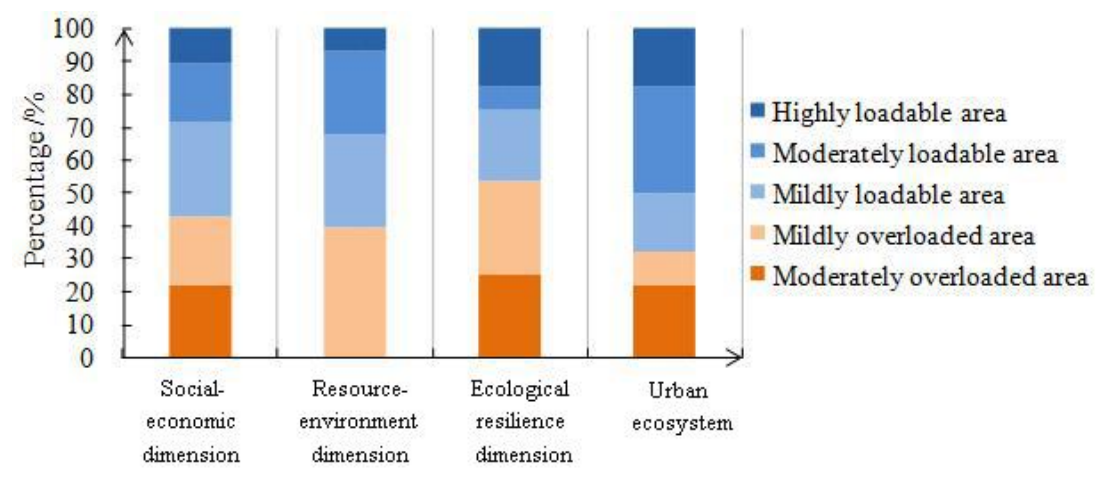

Figure 4. The percentage of each carrying status in each dimension

\section{Analysis of coupling coordination among dimensions of urban ecosystem}

Evaluating the coupling coordination level between dimensions can reveal the advantages and disadvantages of urban ecological carrying capacity in different regions, and to clarify the direction of development, which are of great significance for regional sustainable development. Because there has been less research on coupling coordination between dimensions, this study adopted a two system model and a three system model to assess coordination between the various dimension, which was visualized using ArcGIS10.3 software (Fig. 5).

From the perspective of coupling coordination between socio-economic dimension and resource-environment dimension ( Fig. 5a), cities with high coupling coordination between socio-economic and resource-environment dimensions were mainly distributed in Xiangyang-Jingmen-Yichang urban belt, southern Jiangxi Province, Wuhan and Changsha. Xiangyang and Yichang in central Hubei Province had strong social development and economic coordination. In addition, as a national garden, health, and ecologically livable city, the area is rich in natural resources and fine environment, so the level of coupling coordination between these two dimensions was relatively high. Wuhan and Changsha, the provincial capitals faced higher population pressure, but had higher society development level, economic strength, and high economic development efficiency. In 2015, for example, tertiary industry proportions in Wuhan, Changsha, and 
Nanchang were as high as $51.02 \%, 45.06 \%, 41.22 \%$, but average proportions in their surrounding areas were only $33.09 \%, 35.66 \%$, and $35.77 \%$, so the green economy was prominent. Therefore, the level of coupling coordination between dimensions is high. Low coupling coordination was mainly distributed in the surrounding areas of Wuhan City and southwest of the urban agglomeration around Changsha-Zhuzhou-Xiangtan. The region's social development level and economic strength has largely improved in recent years, but due to poor industrial foundation and undertake "three highs" (high pollution, high energy consumption, high emissions) industrial transfer and so on, it have led to a higher proportion of secondary industries, low economic development efficiency, and weak natural resources and environmental support. Therefore, the level of coupling coordination between dimensions was low. In 2015, for example, the average of primary and secondary industry proportions in the low-value areas around Wuhan and Changsha were as high as $66.91 \%$ and $64.34 \%$, respectively.

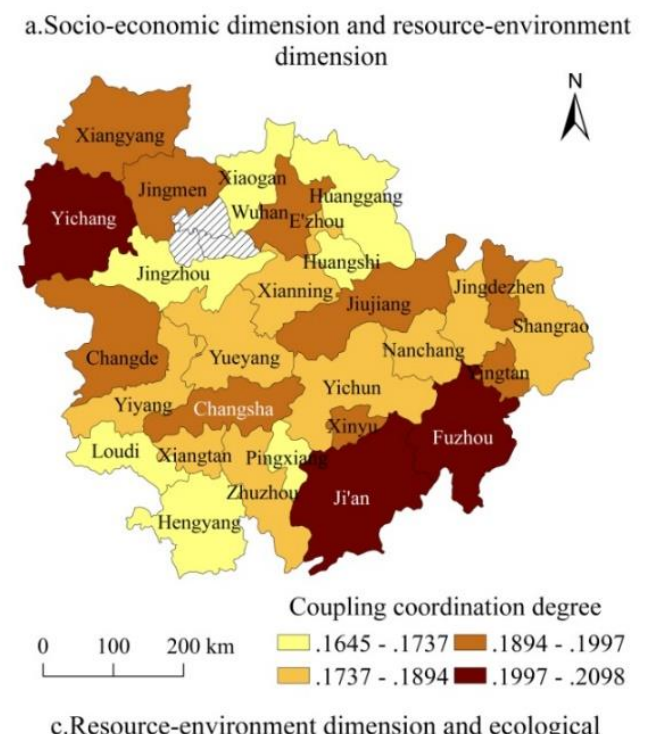

b.Socio-economic dimension and ecological resilience
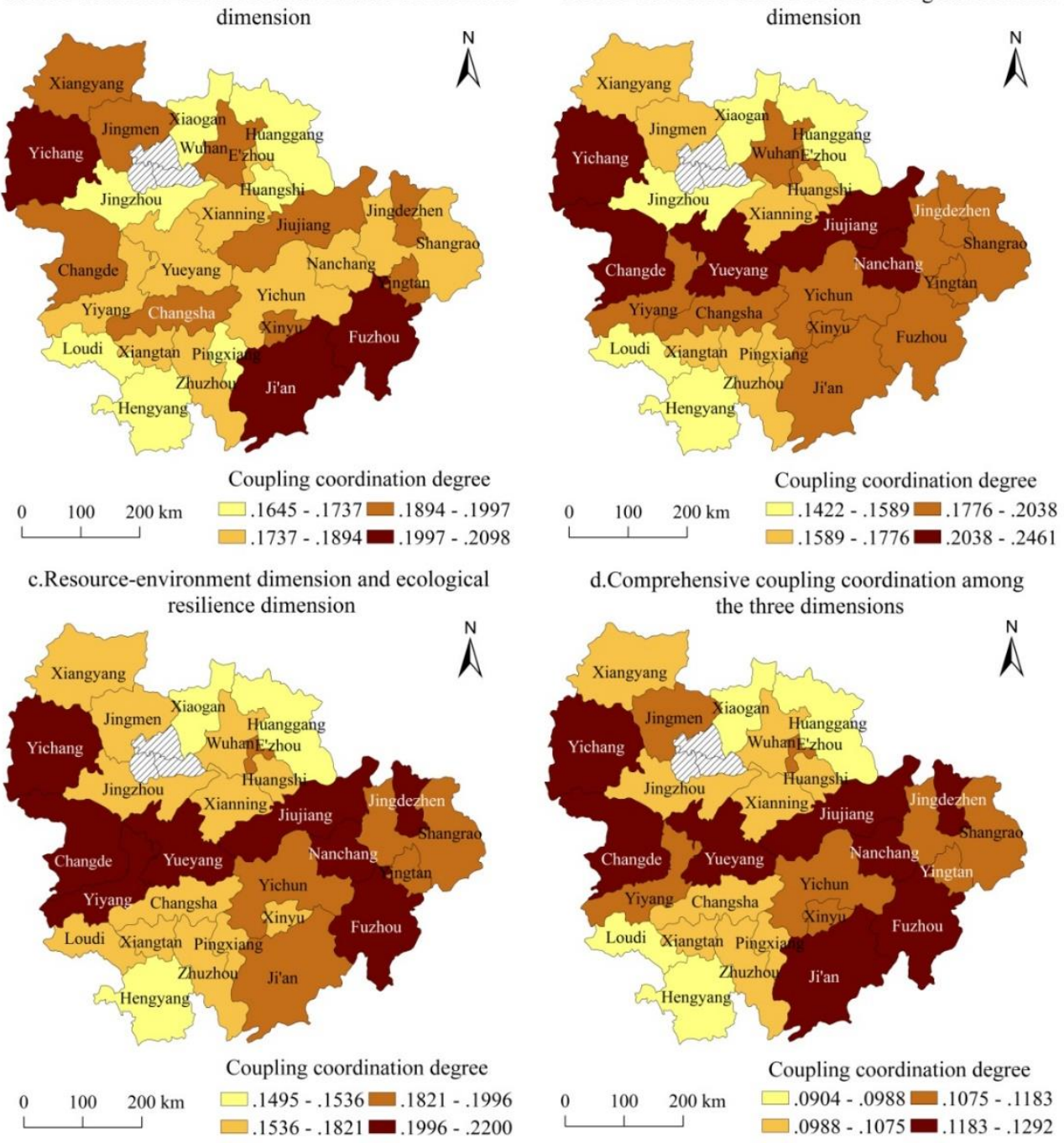

Figure 5. Spatial distribution of coupling coordination between dimensions in the urban agglomeration in the middle reaches of the Yangtze River in 2015 
Cities with high coupling coordination between social-economic dimension and ecological resilience dimensions were mainly distributed in the Poyang Lake urban agglomeration, the area around Dongting Lake, and Yichang City (Fig. 5b). In recent years, the implementation of environmental protection policies around Poyang and Dongting Lake ( 《planning of Dongting Lake ecological economic zone》, 《planning of Poyang Lake ecological urban agglomeration (2015-2030)》, 《eco-environmental protection planning of Yangtze River economic zone》), and under the promotion of the new urbanization development planning( 《National new urbanization plan of China (2014-2020)》), the region gradually transitioned from previous extensive economic development mode to sustainable development with comprehensive attention to environmental protection and social security. Therefore, coupling coordination between the dimensions of social-economy and ecological resilience dimensions in this region was relatively high. As a sub-central city of Hubei Province, Yichang had strong socialeconomic coordination force. In addition, as a national garden and ecologically livable city, it also had a high ecological resilience, so there was high coupling coordination between socio-economic and ecological resilience dimensions. Cities with Low coupling coordination were mainly distributed in the surrounding area of Wuhan and southwest of the urban agglomeration around Changsha-Zhuzhou-Xiangtan. The loss of natural elements and environmental pollution caused by human activities in such areas are prominent. In the future, social security, social services, and economic development efficiency should be further improved on the basis of improving the regional ecological resilience and ecological potential, so as to improve urban ecosystem carrying capacity.

Cities with high coupling coordination between resource-environment and ecological resilience dimensions were mainly distributed in the Poyang Lake urban agglomeration and around Dongting Lake (Fig. 5c). These regions have strong resource and environmental supporting force. On the other hand, as important ecological protection areas in the Yangtze River Basin, Dongting and Poyang Lake areas have abundant forests, wetlands, and other natural elements, and the region has strong ecological regulating force when facing the interference of external natural and human factors. Therefore, the coupling coordination level between resources-environment and ecological resilience dimensions was relatively high. Areas with low coupling coordination levels were mainly distributed in the Wuhan urban agglomeration and southwest of the urban agglomeration around Changsha-Zhuzhou-Xiangtan. This was because rapid urbanization and extensive economic development in this region had significant impact on land use/cover, biodiversity, the hydrological system, local climate, and other factors at different regional scales that resulted in lower resourceenvironmental support and ecological resilience than other regions.

From the perspective of comprehensive coupling coordination among the three dimensions (Fig. 5d), the level of comprehensive coupling coordination between the three dimensions was generally lower than between any two dimensions. Cities with high coupling coordination were mainly distributed around Dongting Lake and the urban agglomeration around Poyang Lake, while cities with lower levels were mainly distributed in the Wuhan urban agglomeration and southwest of the urban agglomeration around Changsha-Zhuzhou-Xiangtan. Their spatial distributions were similar to the patterns observed between the social-economic and ecological elasticity, and between the social-economic and ecological resilience dimensions, and the resources- environment and ecological resilience dimensions. Investigate its reason, the 
three-dimensional carrying capacity levels in the area around Dongting Lake, the urban agglomeration around Poyang Lake, and Yichang City were higher than elsewhere and these areas also had the highest coordination levels. Areas around Wuhan and the southern cities of the urban agglomeration around Changsha-Zhuzhou-Xiangtan have undergone recent improves in the resources-environment dimension, but unbalanced development between urban and rural areas, extensive economic development mode, and the loss of natural elements caused by broad problems, such as low social-economic coordination and ecological resilience, still is the most important reason to resulted in a low level of overall coupling coordination.

\section{Discussion}

\section{Index system for urban ecosystem carrying capacity assessment}

Urban ecosystem is an on-limits, comprehensive "natural - social - economic" compound ecosystem. On the basis of a deep understanding of the concept and connotation of urban ecosystem carrying capacity, we have established a new assessment framework for urban ecosystem carrying capacity, and constructed a multidimensional, multi-index and expanded comprehensive index system of urban ecosystem carrying capacity from macro-scale based on multi-metadata such as earth observation data and socio-economic statistics, it makes up for the lack of comprehensiveness of evaluation system in medium and micro scale research. However, the use of various indicators to represent the urban ecosystem carrying capacity has certain limitations due to the accessibility, representativeness and objectivity of data. For example, urban ecosystem is always in a state of dynamic positive and negative feedback, within the system, system and external environment are continuously carrying on the material flow, energy flow, information flow, and population flow. But in the process of calculating urban ecosystem carrying capacity without considering the interaction of elements and the flow of elements between spatial units, also ignores the transmission effect of urban ecosystem structure, process, and function on urban ecosystem carrying capacity, which is a deficiency in the research (Ji et al., 2017). In future research, we should include more data sources and indicators to improve the accuracy of urban ecosystem carrying capacity assessment. Undoubtedly, although the index system in this paper is not ideal, but it can be easily applied to the rapid urbanization areas of developing countries such as China.

\section{Methodology}

The most important step before the evaluation of urban ecosystem carrying capacity is the preprocessing of index data, including forward processing and standardized processing of the index data. Existing studies mainly divided the types of indicators into forward indicator and reverse indicator (Song et al., 2014; Xiong et al., 2016; Ji et al., 2017), but rarely mentioned the moderate type indicator, and the positive treatment formula of the moderate type indicator has not been clearly explained. The contribution of this study is to attempt to deduce a forward processing formula for the moderate type index and scientifically determined the ideal value for each index, which was helpful in using the state-space method to quantitatively evaluate urban ecosystem carrying capacity. However, the forward processing formula for the moderate-type index still needs further improvement in future studies. Determining the ideal value for the 
individual index requires further discussion. In addition, the ideal indicator value was the standard set in a specific year. As time goes by, the ideal value standard will change and should therefore be constantly updated in subsequent research.

In addition to the preprocessing of index data, the determination of index weight is also an important part in the evaluation of urban ecosystem carrying capacity. In the PDSR model of this paper, the determination of multiple index weights is involved. There is no doubt that the weight of indicators will have an important impact on the final results, so its setting is extremely important. Existing studies (Xiong et al., 2016; Peng et al., 2019) mostly adopt objective weighting methods such as entropy weight method, which eliminates the interference of human factors and makes the determination of index weight objective. Therefore, entropy weight method is selected to determine the index weight in this study. In addition, existing studies have shown that spatial interaction between adjacent research units (Shen et al., 2017) should be considered in studies of large regions or urban agglomerations, but some studies pay less attention to spatial effect in the determination of index weight, which needs to be improved in future studies.

\section{Study scale}

Spatial extent and spatial resolution are collectively described as the spatial scale (Turner et al., 1989; Xiao et al., 2019). In the study of urban ecological carrying capacity, some research areas are administrative districts and some are natural borders. However, with urban ecosystem carrying capacity plays a more and more importance part in macro ecological decision-making, administrative districts as research unit has become the mainstream (Zeng et al., 2016; Xiao et al., 2019; Su et al., 2019).

In terms of spatial resolution, some researches take remote sensing image pixel as the basic research unit, and then carry out micro-scale researches with the help of remote sensing data. Some studies take county-level or prefecture-level administrative districts as basic research units, and then carry out macro-scale studies with the help of statistical data or multivariate data such as statistical data and remote sensing data. Dialectically, studies at different scales all have their own emphases. Macroscopic scale studies based on macroscopic data or multivariate data are suitable for assessing the carrying capacity of composite urban ecosystem, which is helpful for macro ecological decision-making, but accompanied by the loss of micro-information. The micro-scale research based on remote sensing data is suitable for the assessment of the carrying capacity of a single ecosystem. It can perfectly display the detailed information inside the research area and contribute to the detailed planning of the region. However, the type of ecosystem studied is limited. Therefore, there is no perfect scale for the selection of spatial resolution of ecological carrying capacity, only the most suitable scale. According to the research trend, with the continuous development of the concept and connotation of urban ecosystem carrying capacity, the evaluation index of urban ecosystem carrying capacity has been involved in many fields, such as society, economy, ecological environment, pollution control, environmental protection idea, etc., and the single remote sensing data has long been unable to meet the needs of the latest research. Therefore, it has become the choice of more and more scholars to combine statistical data and remote sensing data to carry out research on urban ecosystem carrying capacity at macro scale. 


\section{Future research direction}

At present, the research on ecological carrying capacity has been relatively mature, but the research on urban ecosystem carrying capacity based on complex urban ecosystem is still weak, and many problems need to be further discussed. For example, in this study, the evaluation of urban ecosystem carrying capacity based on state-space method only evaluates the carrying state of urban ecosystem in cross-sectional years. This is because it is very difficult to determine the ideal value of each index in all years, it is unscientific to determine the carrying state of urban ecosystem in all years only by the ideal value of each index in a single year. At present, the evaluation of urban ecological carrying capacity is divided into two categories. Some scholars (Xiong et al., 2014; Ji et al., 2017; Pei et al., 2019) adopted a more flexible method, that is, to compare the change trend of ecological carrying capacity in the same area, in different years or in different regions and in different years through the study of long time series. This method does not determine the carrying state. Another part of scholars (Li and Ma, 2013; Song and $\mathrm{Yu}, 2014$ ) analyzed the bearing state of urban ecosystem in crosssection years according to the second formula of state-space method. In recent years, many scholars have emphasized that it is of great practical significance to carry out spatio-temporal dynamic analysis and simulation prediction of urban ecosystem carrying capacity from long time series (Zeng et al., 2016; Xiao et al., 2019). Based on this, in future research, we should find a suitable method to determine the ideal value of each index in all years, so as to analyze the changing trend of urban ecosystem carrying state in long time series years, so that we may find more interesting and valuable discoveries.

This study is limited by space and fails to make further analysis on the influencing factors of urban ecosystem carrying capacity, but the research on the influencing factors of urban ecosystem carrying capacity is extremely important, and the results play an important role in guiding the improvement of urban ecosystem carrying capacity in different regions by classification. From the existing research results, future research on the influencing factors of urban ecosystem carrying capacity should focus on the following two aspects. First, in the selection of influencing factors, we should expand the scope of influencing factors and quantify regional policies, environmental protection idea and other factors by questionnaire. Secondly, the interaction between influencing factors and the mechanism of influencing factors should be analyzed in detail.

\section{Conclusion}

Multi-source data was used to construct a comprehensive evaluation index system for urban ecosystem carrying capacity. The entropy weight method and state-space method were used to quantitatively evaluate urban ecosystem carrying capacity in the urban agglomeration in the middle reaches of the Yangtze River in 2015. A coupling coordination degree model was then used to analyze the spatial distribution characteristics of coupling coordination degree between dimensions and the reasons for spatial heterogeneity. The conclusions are as follows:

(1) Urban ecosystem carrying capacity in the urban agglomeration in the middle reaches of the Yangtze river presents a significant north-south spatial differentiation pattern, and it had obvious spatial characteristics of homogeneous agglomeration. The social-economic coordination force dimension had a circling spatial structure extending outward from the provincial capitals of Hubei, Hunan, and Jiangxi Provinces. The 
resource-environment supporting force and ecological resilience dimensions had similar spatial patterns. Overloaded area was mainly distributed in core area of the Wuhan urban agglomeration and the urban agglomeration around Changsha-Zhuzhou-Xiangtan, which was mainly caused by large resource supply pressures and environmental loads, as well as the massive loss of natural elements.

(2) Wuhan and Changsha have greater population pressure, but thanks to a higher level of social development, economic strength, and economic development efficiency, so the coupling coordination between the socio-economic and resource-environment dimensions was high. In the surrounding area of Wuhan City and southwest of the urban agglomeration around Changsha-Zhuzhou-Xiangtan had low coupling coordination due to the poor industrial foundation, low economic development efficiency, and heavy resource consumption and environmental load. The spatial distribution characteristics of the coupling coordination between the socio-economic and ecological resilience dimensions were similar to those of the resource-environment and ecological resilience dimensions. The area around Dongting Lake, the urban agglomeration around Poyang lake, and Yichang City all had high levels of coupling coordination.

(3) The cities with higher coordination levels were mainly distributed around Dongting Lake and the urban agglomeration around Poyang Lake, while the cities with lower coordination levels were mainly distributed in the Wuhan urban agglomeration and southwest of the urban agglomeration around Changsha-Zhuzhou-Xiangtan. In these areas, weak social-economic coordination and ecological resilience were caused by the imbalance between urban and rural development, extensive economic development, and the loss of natural elements, which need to be paid more attention in the future.

Acknowledgements. We are very grateful to Yushi Zhou for his great assistance in data processing. We are also very grateful to professor Yaochen Qin and professor Fengxian Lu for their professional advice in this study, Zhixiang Xie for his help in research methods. We would also like to thank the National Natural Science Foundation of China (No. 41671536; No. 41501588) for providing the funding for this research.

\section{REFERENCES}

[1] Chen, Z. S., Wu, Z. Q. (2017): The change trend of the average consumption tendency between urban and rural areas in China -- based on the perspective of the difference of the average consumption tendency between urban and rural areas. - Economic Perspectives (8): $18-30$

[2] Chen, D. L., Lu, X. H., Kuang, B. (2018): Dynamic evolution and spatial convergence of urban land use efficiency in the middle reaches of the Yangtze River. - China Population, Resources and Environment 28(12): 106-114.

[3] Cui, F. J., Yang, Y. S. (1997): A study on the time-space distribution features and utility intensity of the TEBC resource of MT. TAI. - Geographical Research 16(4): 48-56.

[4] Ge, L. Q., Li, S. M., Xie, G. D., Cheng, Y. P., Ni, Z. S. (2016): The population carrying capacity of waters ecosystem in China. - Journal of Resources and Ecology 7(1): 21-27.

[5] Hadwen, P. (1922): Reindeer in Alaska. - US Dept of Agric 1089: 18-24.

[6] He, R. W., Liu, S. Q., Liu, Y. W. (2011): Application of SD model in analyzing the cultivated land carrying capacity: A case study in Bijie Prefecture, Guizhou Province, China. - Procedia Environmental Sciences 10: 1985-1991. 
[7] Hu, B. M., Wang, Z. S., Wu, J. J., Li, W. G. (1992): Structural index system of agroecosystem and their quantitative methods. - Chinese Journal of Applied Ecology 3(2): 144-148.

[8] Hudak, A. T. (1999): Rangeland mismanagement in South Africa: failure to apply ecological knowledge. - Human Ecology 27(1): 55-78.

[9] Ji, X. P., Bai, Y. P., Du, H. B., Wang, J. B., Zhou, L. (2017): Research on the spatial quantitative evaluation and coupling coordination degree of ecological carrying capacity in Gansu Province. - Acta Ecologica Sinica 37(17): 5861-5870.

[10] Jiao, W. J., Min, Q. W., Cheng, S. K., Zhang, D., Sun, Y. H. (2011): The emergy-based ecological footprint (EEF) of traditional agricultural areas in China: A case study of Congjiang County, Guizhou Province. - Journal of Resources and Ecology 2(1): 56-65.

[11] Jin, Y., Lu, Z. H., Tan, F. F., Zhang, M., Zhang, H. Y. (2015): Assessment of ecological carrying capacity on the typical resources-based cities: a case study of Tangshan City. Acta Geographica Sinica 35(14): 4852-4859.

[12] Lein, J. K. (2010): Mapping environmental carrying capacity using an artificial neural network: A first experiment. - Land Degradation\&Development 6(1): 17-28.

[13] Li, N., Ma, Y. J. (2013): Analysis of spatial difference of ecological carrying capacity and its influencing factors in Liaoning Province. - Journal of Arid Land Resources and Environment 17(3): 8-13.

[14] Li, Y. F., Li, D. (2014): Assessment and forecast of Beijing and Shanghai's urban ecosystem health. - Science of the Total Environment 487: 154-163.

[15] Li, H., Huang, X. J., Jin, Y. Z., Zhang, X. (2017): Population Carrying Capacity of Water Resources in the Yangtze River Economic Belt. - Economic Geography 37(1): 181-186.

[16] Mondino, E. B., Fabrizio, E., Chiabrando, R. (2014): A GIS Tool for e Land Carrying the Capacity of Large Solar Plants. - Energy Procedia 48: 1576-1585.

[17] O’Neill, D. W., Tyedmers, P. H., Beazley, K. F. (2007): Human appropriation of net primary production(HANPP) in Nova Scotia, Canada. - Regional Environmental Chang 7(1): 1-14.

[18] Pan, H. Y., Zhu, W. Q., Cui, L. Y., Feng, M. Q., Zhu, F. (2017): Spatial differences in per capita ecological footprint and per capita ecological carrying capacity in Chengdu. - Acta Ecologica Sinica 37(19): 6335-6345.

[19] Pei, Y., Yang, J., Li, B. X., Li, X. M., Ge, Y. T. (2019): Study on spatial-temporal differentiation of eological carrying capacity in urban fringe areas at community scale: A case study of Ganjingzi District in Dalian. - Acta Ecologica Sinica 39(5): 1715-1724.

[20] Peng, J., Du, Y. Y., Liu, Y. X., Hu, X. X. (2016): How to assess urban development potential in mountain areas? An approach of ecological carrying capacity in the view of coupled human and natural systems. - Ecological Indicators 60: 1017-1030.

[21] Peng, B. H., Li, Y., Elahi, E., Guo, W. (2019): Dynamic evolution of ecological carrying capacity based on the ecological footprint theory: A case study of Jiangsu province. Ecological Indicators 99: 19-26.

[22] Qi, H. Q., Xi, X. W., Gao, Q. Y. (2015): Measurement on the development level of China's urbanization and the time-varying characteristics of the effects of economic growth. - Economist 17(11): 26-34.

[23] Rong, Y. J., Guo, X. Y., Du, S. X., Li, X., Ning. T., Zhang, M. Y. (2019): Study of Ecological Carrying Capacity Using PSR Model Based on Ecosystem Services and Ecological Sensitivit. - Research of Soil and Water Conservation 26(1): 323-329.

[24] Rudolph, A., Figge, L. (2017): Determinants of ecological footprints: What is the role of globalization. - Ecological Indicators 81: 348-361.

[25] Shen, W., Du, Q. Y., Li, Y. H., Zhao, W., Lu, F. X., Zhou, Y. S., Shen, Z. F. (2017): Study on the spatial-temporal pattern evolution and influencing factors of the new urbanization in the Yangtze River Economic Belt. - Journal of Central China Normal University (Natural Sciences) 51(4): 534-541. 
[26] Sjafrie, N. D. M., Adrianto, L., Damar, A., Boer, M. (2018): Human appropriation of net primary production (HANPP) in seagrass ecosystem: an example from the east coast of Bintan Regency, Kepulauan Riau Province,Indonesia. - Environment, Development and Sustainability 20(2): 865-881.

[27] Song, Y. C., Yu, D. (2014): Evaluation of comprehensive capacity of resources and environments in Poyang Lake Eco-economic Zone. - Chinese Journal of Applied Ecology 25(10): 2975-2984.

[28] Su, M. R., Xie, H., Yue, W. C., Zhang, L. X., Yang, Z. F., Chen, S. H. (2019): Urban ecosystem health evaluation for typical Chinese cities along the Belt and Road. Ecological Indicators 101: 572-582.

[29] Turner, M. G. (1989): Landscape ecology: the effect of pattern on process. - Annual Review of Ecology and Systematics 20(20): 171-197.

[30] Wackernagel, M., Galli, A. (2007): An overview on ecological footprint and sustainable development: A chat with Mathis Wackernage. - International Journal of Ecodynamics 2(1): 1-9.

[31] Wang, J. J., Yao, X. H., Li, J. R., Chang, H., Wang, Y. G. (2000): Assessment for Ecological Carrying Capacity of Heihe River Basin. - Research of Environmental Sciences 21(2): 44-48.

[32] Wang, W., Zhang, T., Wang, X. W., Wen, C. H. (2017): Spatial and temporal pattern of urban ecological carrying capacity in Yangtze river economic zone. - Resources and Environment in the Yangtze Basin 26(12): 1963-1971.

[33] Wang, Y. J., Xie, B. G., Li, X. Q., Zhao, W. Q., Wang, J. Y., Luo, H. B. (2017): Ecosystem carrying capacity balance of the Karst region in China, based on the supply and demand of cultivated land. - Acta Ecologica Sinica 37(21): 7030-7038.

[34] Xiang, X. R., Pan, T., Wu, S. H., Liu, W. D., Ma, L., Wang, X. F., Yin, Y. H., Li, J. (2016): Assessment and prediction of ecological carrying capacity for the Northern Slope Economic Belt of Tianshan Mountains. - Geographical Research 35(5): 875-884.

[35] Xiao, Z. X., Peng, Y. Z., Li, S. L. (2013): Chinas optimal industrial structure: The theoretical model and quantitative calculation. - China Economic Quarterly 12(1): 135162.

[36] Xiao, R., Liu, Y., Fei, X. F., Yu, W. X., Zhang, Z. H., Meng, Q. X. (2019): Ecosystem health assessment: A comprehensive and detailed analysis of the case study in coastal metropolitan region, eastern China. - Ecological Indicators 98: 363-376.

[37] Xing, L., Xue, M. J., Hu, M. S. (2019): Dynamic simulation and assessment of the coupling coordination degree of the economy-resource-environment system: Case of Wuhan City in China. - Journal of Environmental Management 230: 474-487.

[38] Xiong, J. X., Peng, B. F., Chen, D. L., Wang, Y. L., Zhang, M. (2013): Temporal and spatial evolutionary feature of ecological carrying capacity in Dongting Lake region. Geographical Research 32(11): 2031-2040.

[39] Xiong, J. X., Chen, R. L., Peng, B. F., Deng, S. T., Xie, X. M. (2014): Spatio-temporal Difference of Coupling Coordinative Degree of Ecological Carrying Capacity in the Dongting Lake Region. - Scientia Geographica Sinica 34(9): 1108-1116.

[40] Xiong, J. X., Chen, L. D., Peng, B. F., You, X. J. (2016): Temporal and Spatial Difference of Dynamic Simulation of Ecological Carrying Capacity in Dongting Lake Region. - Economic Geography 36(4): 164-172.

[41] Yang, Z. F., Sui, X. (2005): Assessment of the ecological carrying capacity based on the ecosystem health. - Acta Scientiae Circumstantiae 25(5): 586-594.

[42] Yin, P. J., Du, S. Y., Bai, Z. P. (2011): Analysis and evaluation of the ecological carrying capacity of 17 cities in Shandong Province in 2008. - Acta Scientiae Circumstantiae 31(9): 2048-2057.

[43] Zeng, C., Deng, X. Z., Xu, S., Wang, Y, T., Cui, J. X. (2016): An integrated approach for assessing the urban ecosystem health of megacities in China. - Cities 53: 110-119. 
[44] Zhang, Y., Yang, Q. Y., Min, J. (2016): An analysis of coupling between the bearing capacity of the ecological environment and the quality of new urbanization in Chongqing. - Acta Geographica Sinica 71(5): 817-828.

[45] Zhou, T., Yin, Q. (2012): The Urban Land Ecosystem Health Evaluation in Chengdu City. - Earth Science Research 1: 297-302.

[46] Zhou, W., Zhao, G. Q. (2012): China's GDP Growth and CPI: Relationship, Equilibrium and Target Control for the 12th Five-Year Plan. - Economic Research Journal 47(5): 4-17.

[47] Zhu, Y. Z., Xia, J., Wang, G. S. (2005): Assessment of water resources carrying-capacity with multi-criteria scenario analysis method: a case study in Zhangye region. Geographical Research 24(5): 732-740. 